\title{
KORTE OPMERKINGEN OVER BALINEESCH EN KAWI.
}

(Medegedeeld uit brieven van $\mathrm{D}^{\mathrm{r}}$. H. N. VAN DER TUUK.)

Ten vervolge op 't medegedeelde in 't 1 ste stuk van 't 6 de deel der Bijdragen en in 't 2 de van 't 5 de deel, worden hieronder uittreksels uit latere brieven van Dr. van der Tuuk in 't licht gegeven.

H.K.

\section{Boeleleng, 24 April.}

"In mijn vorigen brief heb ik gesproken van de spelling taněmangku, d. i. taněman en ku. Volgens een dergelijken euphonischen regel heeft de verandering plaats van $r$ na eene sluitende $n$ in ling. $d$; bijv. wangundahina, in plaats van wangun rahina; tandahayu in plaats van tan rahayu ${ }^{1}$.

Het behoort hier tot de godsdienst, stukken uit de Kawigedichten op te dreunen. Zooals het gaat, waar de godsdienst in. 't spel is, men verbeeldt zich wel eens iets te weten, dat voor een ongeloovige duister is. Van daar dan ook, dat velen stukken van buiten kennen waarvan zij geen vertaling kunnen geven. Alleen de geleerden, meestal Brahmanen, weten een soort van verklaring te leveren. Nog gisteren hoorde ik eene verklaring die kant noch wal raakt, ofschoon de plaats niet moeijelijk is. In den Wiwâha bl. 81, r. 9 v. o. wordt manthana algemeen verklaard door balé. Niemand wist me te zeggen dat udadhimanthana "'t karnen van de zee" beteekende, en toen ik den regel voor hen vertaalde met: "'t dak er van was doorschijnend edelgesteente waarop gebeiteld was eene voorstelling van 't karnen der zee (door de goden bij 't zoeken naar 't

1 Deze euphonische regel, waarvan nog sporen in 't nienw Javaansch over zijn, bijv. in pindo $=$ pin ro, en dit voor ping ro, moet ondtijds veel algemeener geweest zijn. Volmakt gelijk in 't Kawi gaat in 't Alfoersch der Minahassa un rani over in undani. Zie Niemann's Bijdr. tot de kennis der Alfoersche taal, bl. 43. Strikt genomen, kan men niet zeggen dat overal $r$ ouder is dan $d$ (linguale $d$ ), of omgekeerd; het zijn tweelingen

HK. 
Amrĕta)", stonden ze verbaasd en gaven me eindelijk toe, daar hun de beteekenis van udadhi wel bekend is. Sommige humner verklaringen zijn zeer ingenieus, al moet men ze eerst door andere voorbeelden staven; zoo bijv. Bhauma-kâwja, bl. 17 r. 5 v. o. wordt bhaganjdjing door balé verklaard, terwijl rinjtju een fout is voor rinjdjung (bouwvallig). - Ik heb hier zeer onlangs de bewijzen gevonden van een feit dat niet van belang is ontbloot: vele HH. alhier zijn afgeschreven naar exemplaren in een schrift dat men niet goed meer lezen kon. Hoe anders is het mogelijk dat men in pl. van $g h$, waar deze pasangan is, zoo vaak $g y$ vindt? De pasangan der $g h$ moet dus in dit schrift veel geleken hebben op de pasangan der $g$ met $j$, van daar telkens sanggja in pl. van sanggha (zie Wrětta sanjtjaja, in de transcr. bl. 6); djanggja kent men hier algemeen in de beteekenis van "been" (vgl. Wiwâha, zang II, 18, als verklaring van wětis) en dit woord kan niets anders zijn dan skr. djangghấ; çrî Airlanggja de naam van den vorst onder wiens regeering de Wiwâha opgesteld werd (vgl. verslag van Friederich, bl. 18 en Wiwâha, slotvers); deze vorst heeft eigenlijk çrî Airlanggha geheeten.

In de Balin. interlineaire vertalingen komen woorden voor die tot een nieuwer Kawi behooren; bijv. siratmaja en tấrdjdja (beide "wenkbraauw "); dwipak en dipak "olifant," uit dwipa; de $k$ hierin is vrij onverklaarbaar, vgl. echter manik met man $i$, Mal. tabik met Batav. santabi; (zie Bat. Wdb); wiplatwang (zich uit de voeten maken, ontsnappen). Ook nurodja [waarvan reeds in eene vorige mededeeling gesproken is] behoort tot dat moderne Kawi, en evenzeer tist $a$ (Wiwâha, bl. 91 r. 1 en 6); zoo ook dwaratna als verklaring van manggista (vgl. Mal., Jav. manggis)."

\section{APrIL.}

Verscheiden malen ben ik hier tegenwoordig geweest bij 't mëpudja of měwéda van den Padanda, en heb dan gehoord dat de Weda's hier half in 't Kawi zijn. Door den zingenden dreun kon ik 't verband niet vatten, maar vele uitdrukkingen verstond ik dadelijk; o. a. hoorde ik ganggâdwấre "aan den ingang van den Ganges," pushpěm (zoo spreekt men hier pushpam uit), ri padanira "aan zijn voeten," en eene optelling der 30 Wukus. Later zie ik kans zoo'n geheele pudja u over te brieven wat de kwintessens betreft. 
Ik heb hier drie HH. van de Adiparwwa van de MahâBhârata vergeleken, doch zie nog geen kans een goeden tekst er van over te zenden. Ik lasch hier een stuk in, dat voor de redactie van de Mahâ-bhârata in ${ }^{~ t}$ Kawi ${ }^{1}$ eenig licht verspreidt. Gij kunt er uit zien dat de fouten aan de afschrijvers te wijten zijn. Zulk eene spelling als suptika, in plaats van sauptika, is misschien reeds oud (zie echter onder, alwaar soptika). ${ }^{2}$

Mijn spelling ta nparatra in plaats van tanparatra; ri nyswargga in plaats van ring swargga zal u verwonderen, maar is toch de eenige ware, dewijl die ingevoegde letters bij 't volgende woord hooren; hierover een andermaal. 't Bovenstaande ${ }^{3}$ is nog al duidelijk, hoewel krielende van slordigheden. Panita beteekent "dobbelspel" (nita vindt ge in den Wiwâha tweemaal met tjuki verklaard). ${ }^{4}$ Pangartta in plaats van parlârtha kan er door; nmangpuluh in plaats van nëmpuluh is algemeen in de Kawi-gedichten; maka mag niet van 't volgende woord gescheiden worden, evenmin 't passive pinaka, daar het een prefix is. Het geleuter van de Javanen verdient geen aandacht; zij hebben er mongkå en pinongkå van gefabriceerd! De spelling rwâ voor rwa houd ik voor eene Balineesche voornaamheid. De Balinees spreekt de $a$, als sluitklank, met een gesloten mond uit, zoodat men een klank hoort die 't midden houdt tusschen

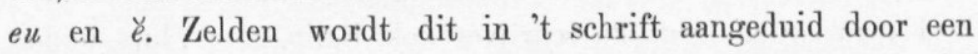
Pĕpĕt; een voorbeeld is ktě "stotferen", dat kětă moet uitgesproken worden; vgl. Bataviaasch Mal. kěta, ook kětak (bij Homan, bl. 13 staat foutief kětak met opgeslokte $k$ ). Dat deze korte klank in 't schrift niet bijzonder uitgedrukt wordt, is geen wonder, daar hij vóór een aanhechtsel weder $a$ is, bijv. umâ, doch bepaald umànné.

1 Niet te verwarren met het Bharata-Yuddha, welk gedicht door Mpu Sědah vrij bewerkt is, en te vergelijken, niet zoo zeer met het ware groote Indische heldendicht, als met het Bhârata-campu, en dgl.

H. K.

2 Hetgeen in den brief volgt, is hier achter opgenomen als afzonderlijk stuk, onder den titel: Inhoudsopgave van 't Mahâbhârata in Kawi. H. K.

3 D. i. de Inhoudsopgave hierachter. H. K,

4 Panita is 't Skr. panita "op 't spel gezet," en ook "op 't spel gezet hebbende;" substantief is panitam "het op 't spel gezette." Nita hangt zonder twijfel, gelijk v. d. T. te kennen geeft, met panita zamen; het is echter niet het ware grondwoord, maar eene verkeerde abstractie, dewijl men $p a$ in panita voor het inheemsche voorvoegsel aanzag.

H. K. 
Ge vraagt me eene proeve van 't [Balin. Kawi] Wdb. Krĕtabasa, maar is de vroeger gezondene $\mathrm{u}$ niet voldoende om er uit te zien welke Indische Kosha ten grondslag heeft gestrekt? 1 Daar ge daaraan niet genoeg hebt, deel ik hier de woorden meê voor "water", (Bal. jèh of ijèh): angjang dalěmmer (sanghjang dalěm er?), s'lodaka, meghapushpa ("wolkbloem?"), nilala, udaka, mani, amba, ambara, puspara, ganarasa, wasiwwa, winjtjira (elders: witjira), hermmi, humbal, pega, warih, tirtta, digikâ, çara, sarasi, toja, banju, apah, dahé, dalěm, kali, pushkari, humirwa, tomi. Sommige van deze woorden, zoo als meghapuspha en ghanarasa ("wolksap") zijn denkelijk gefabriceerd. Wegens de corruptie van 't HS. is het mogelijk dat het schrijffouten zijn. Bepaaldelijk houd ik hermmi, humirwa en tomi alle drie voor schrijflouten in plaats van urmmi (golf), dat vaak in 't Kawi gebezigd wordt; pega zal wel een fout wezen in plaats van megha. Als men puspara vergelịkt met pushkara, komt men tot het besluit dat de opsteller der Krĕtabasa het al heel mooi heeft willen maken door de woorden van verschillende corrupte exemplaren bij elkaar te voegen. De schrijver, of afschrijver van mijn exemplaar, neemt het niet naauw met de beteekenissen; zoo geeft hij onder de woorden voor zee (Balin. pasih, Kawi pasir) ook op setubandha (dam). Dit is vrij zonderling daar het woord uit de Râmâyana bekend genoeg kon wezen. Onder de Kawiwoorden heeft de schrijver ook Balin. gezet; bijv. onder de woorden voor hout ook saang (Balin. brandhout). De volgende woorden die Maan beteekenen, zijn voor 't meerendeel wel te corrigeeren. $1 \mathrm{k}$ geef ze hier zonder er iets bij te voegen. Ge kunt er uit zien hoe weinig waarde de Krětabasa heeft zonder andere exemplaren er bij te vergelijken. Zie hier: subhrângsu, çuddhângsu, niçapati, dwidjaradja. susama, paramajodha, indu, niçanas'ta, sitângsu, çaçalanjtjana, mrěgângka, tjandrama, soma, wind $u$, tarapati, çaçih, us'adipa, himângsu, uwupa, aridja, niçâkara, himaravi, çaçirangsa, gimirat, sitaraçmin, kama, sahuntru, çaçadhara, lek, utipa,

1 In de Krětabasa zijn de synoniemen van elk woord veel talrijker dan in eenigen Indischen Kosha. Alleen uit de volgorde der artikelen zou men kunnen opmaken welke Indische bron inzonderheid gevolgd is. Zoo ver ik tot nog toe over de zaak kan oordeelen, zijn in 't Kawi-Wdb. meer dan een Kosha verwerkt.

H. K, 
gitakara, indwa, grěhara, çaçângka, mrĕgângsu, dikbaja, çaçavungkukan.

\section{MeI.}

In 't afdrukje 1 staat een fout die nog al erg is, namelijk $i k u$ als Balineesch opgegeven. Het is $i k \hat{u}$, en Kawi, Balin. ikuh (niet zoo vaak gebruikt als ikut), Mal. ikur. Hierbij geldt dezelfde klankwet als in Jav. apu= Balin. apuh, Tag. apug, Bataksch apur (overgebleven in napuran; zie Bat. Wdb.), Mal. kapur (uit $k a+$ apur; zie Tob. Spr.) Bij 't lezen van Kawi-werken door Balineezen afgeschreven mag men op deze $h$ wel letten; zoo vindt men telkens nyиh (Mal. njijur), een Balinisme in plaats van ny (Kawi "kokosnoot" of "- boom"). In Bhaumakâwja ziet ge er een voorbeeld van op bl. 17 r. 4 . Dat ge tyasěn naast twasěn gevonden hebt is zeer vreemd, want het eerst is eene verbastering thuis behoorende in de moderne Jav. poëzie, even als kepjan van kepwan, uit den grondvorm ipu, waarvan mepu. Zelfs de moderne Kawi-werken, gelijk de Wasèng en de Malat, hebben nooit tyas voor twas. ${ }^{2}$ Ik heb vroeger beweerd dat het Kawische twas etymologisch $=$ Mal. těras is, zonder nog te weten dat twas in 't Kawi ook "hardheid, duurzaamheid, kracht, voortreffelijkheid" beteekent (vgl. Jav. $t o s$, atos); zie Bhaumak 1, r. 5 v. $0 .{ }^{3}$

De oorsprong van Balin. modre weet ik niet. Een vreemd woord moet het wel wezen, daar het alleen in de taal gebezigd wordt van individu's uit de 3 hoogste kasten; anders zegt men kantjing, dat ook Mal. en Jav. is. ${ }^{4}$ Er zijn hier meer woorden van vreemden oorsprong die ik niet thuis kan brengen; bijv. djalèr "broek." Broeken zijn geen nationale kleederdracht bij de Balineezen, evenmin als bij de Bataks, welke een Arab. Mal. woord daarvoor genomen hebben (zie onder sarawar, in 't Bataksch Wdb.) Vandaar date lanjljingan hier niets anders

1 Van de mededeeling in 't 2e stuk van 't 5e deel der Bijdragen.

2 Maar 't Bharatayuddha in Kawi heeft een ander dnidelijk sprekend voorbeeld, nl. kilyan voor kulvan (48) zoodat tyas naast twas, en dgl. eerder opzettelijke wijzigingen, misschien op gewestelijke nitspraak berustende, zijn dan eenvondige verbasteringen.

H. K.

3 De oorspronkelijke beteekenis zal wel wezen "pit, kern," vgl. Skr. săra.

H. K.

4 Mij was de zin van modre onbekend; door v. d. Tuuk er over ingelicht dat het "knoop" beteekent, zie ik nu wel in dat het 't Jav. mundri "de knoop op een Kopyah" is, wellicht Skr. pundra "moesje, sieraad," enz. H. K, 
beteekent dan een slip die vóór de beenen van den gordel afhangt, en niet, zoo als in 't Jav., broek. Waarschijnlijk zijn er in 't Balin. Bugineesche en Chineesche woorden. Zoo noemt men hier een schoen of pantoffel tlumpah (Chineesche uitspraak van 't Mal. těrumpah). Het Maleisch der Balin. Mohammedanen is dan ook sterk vermengd met Bugineesch of Makassaarsch; van daar laso (Mak.) voor membrum virile. De Balin. Mohammedanen - in 't voorbijgaan gezegd - noemen de zwarte streepjes onder de oogen, in gebruik uitsluitend bij Mohammedanen, tjilak, en niet, zooals in 't Maleisch tjělak. Met opzet is voor hen $\check{e}$ in $i$ veranderd, omdat ljělak (eigenlijk "angel", als die eener bij) in 't Balin. gewoonlijk membrum virile aanduidt.

Het woord ashtaseni komt in goed Kawi voor en wordt in een brokstuk der Tantrî verklaard met wedika. In 't Adiparwa (bl. 4.2 van mijn HS.) wordt van Djanamedjaja gezegd: yogjâbhishekan sang Djanamedjaja çinantyan ${ }^{1}$ de dang-hyang ashtaseni mwang sang brâhmana purohita wedapâraga."

\section{MeI.}

De priestermuts welke de Padanda slechts bij 't mapudja op heeft, heet kě̌lu. Daar achteraan zit een Garuda-kop, naar achteren ziende, van daar garuda mungkur. Is dit ook Indisch 2? De priestermuts heet ook bawa, zooals reeds door Friederich is opgegeven. Met kětu wordt djatâ ${ }^{3}$ in den Wiwâha (bl. 23 , r. 3 v. o.) verklaard, waaruit ge zien kunt dat de Balineezen naar 't verband vertalen. Van de Indische kluizenaars heeft men hier geene voorstelling, zoodat alle woorden die zoo'n theosooph aanduiden, met padanda of pandita vertaald worden. Bij den gemeenen man is dukuh, madukuh "kluizenaarsleven leiden," padukuhan "kluis," in 't geheel niet bekend. Geen enkele godennaam is bij hen bekend. Wat Friederich over de godsdienst alhier mededeelt is grootendeels aan Brahmanen ontleend, zonder dat er op gelet is in hoeverre 't volk er iets van weet. Zoo bijv. is guduha "rozen-

1 Dit çinantyan is een dergelijk voorbeeld, als tyas en kilyan van de vervorming eener to tot $t y$; sindntwan, çinantwan, eig. "vleiend toegesproken", voorts "aangesproken", is gevormd van 't Skr. säntiva, çântiva.

H.K.

2 Als zoodanig mij niet bekend.

H.K.

3 D. i. de haarvlecht, opgebonden haarbos der Indische kluizenaars. 
krans" Kawi en slechts bij geleerden bekend. In de Smaradahana heeft men het verklaard met pawilangan "waarmede geteld wordt." Oshadhi (Bhaumak. bl. 2, r. 2. v. o.) wordt in de Smaradahana verklaard door koçaljawarini, in Râmâj. als een naam opgegeven van de wiçaljaharini, en in een fragment van het Bhaumak. met interlineaire vertaling met wisaljawarini weêrgegeven. De plaats in Râmâj. is de duidelijkste; zij staat in de $22^{\text {ste }}$ Sarga, zang 3 , vs. 23 , vgg., waar we lezen dat Rậma, medelijden hebbende met de menigte van gesneuvelden, Hanumân beveelt 't levendmakende geneeskrachtige kruid (mahoshadhômrětamaja) tẹ halen, opdat de lijken door de kracht er van zouden herleven; nu volgen vs. 23 en 24:

kahanânikang parama oshadhî çikaraninggunung Himagiri tuwuhamningoshadhilatâ ngaranya karĕngö wiçalyaharini, mrětadjîwaningbranita sandhinîjata kinonakĕn susupana tamatarwihang lumaku sang Marutsuta mibĕr těkeng Himagiri.

sira tapwa jar wruhirikangmahoshadhi glânakepwanangadĕg wěkasan pupak ta ikanang gunung nibĕrakĕnya sakshana datĕng, saha mûlamulja milu tangmahoshadhi katût katonyatamalah inalap ta denira narârjja jeka panirâmirengmati kabeh.

Deze twee strofen zijn niet zonder fouten, doch overigens zeer duidelịk (vgl. den Jav. Râma, ed. Winter, bl. 130, vgg.) 1. Maar hoe komt dit oshadhi op de aangehaalde plaats van 't Bhaumak. te pas? Uit de plaats van de Smaradahana blịkt het een licht gevende plant te zijn ${ }^{2}$ : "söngsöng ningoshadhilatâ kumĕnjar damarnya," d. i. volgens Balin. vertolking: "tedjaningkoçâljawarini ngredep makapadyutnya," d. i. "de luister van 't oshadhi-kruid ${ }^{3}$ lichtte hel, het (paleis) tot lamp dienende."

1 De drie bovenvermelde vormen van 't kruid zijn alle verhaspeld uit skr. viçalyakaran meermalen voorkomende, o. a. juist in de parallelplaatsen van 't skr. Râmâyana; nl. Boek VI, 71,$23 ; 82,113$. Niet onjuist ware een bijvorm viģalyakáriní, ofschoon die niet aangetroffen wordt.

H.K.

2 Niet zoozeer een bijzonder kruid schijnt er in Bhaumak. en Smarad. bedoeld, als wel ettelijke kruiden, mahaushadhi genaamd, waaronder 't kruid sanjīwaní geacht werd de eerste plaats in te nemen. Zie o. a. Kalidâsa's Kumâra-sambhawa, I, 10 en 2.

H.K.

3 Oshadhi-lata is door de Balin. niet geheel juist opgevat; het beteekent "kruiden en (slinger) plauten." 
De boven aangehaalde strofen uit Râmay. schijnen vrij corrupt te zijn; in pl. van kahanânikang lees kahanannikang ${ }^{1}$; in pl. van panirämireng lees paniramnireng.

De hooge taal alhier wordt geheel anders toegepast dan op Java. Den rechten naam er voor heb ik nog niet kunneu vinden, dewijl de Balineezen die taal nu eens basa singgih, dan weder basa menak of basa natya of basa bakti noemen. Deze namen gelden zoowel van hetgeen men op Java Krama, als op hetgeen men aldaar Krama inggil heet. Deze taal bevat de woorden welke van een voornaam persoon gebezigd worden, terwijl 't Krama die bevat, welke jegens zulk een persoon te pas komen. Deze taalsoort is in 't Balin. niet zoo ontwikkeld als de eerste; zoo bijv. kan men jegens eenen meerdere zeggen didja "waar?" terwijl men dan in 't Jav. pundi voor ěndi zou bezigen. De woorden die gebruikt worden van eenen meerdere, d, i. iemand uit de 3 hoogste kasten, anak menak, of iemand die wegens ouderdom of ambtsbetrekking onderscheiding verdient, zal ik de "voorname" noemen, daar zij van voorname personen gebezigd wordt, en de andere de "hooge." Bijv. grija kan een Javaan, jegens zijn meerderen sprekende, van zijn eigen huis zeggen; niet zoo in 't Bal., alwaar het bepaaldelijk de woning eens Brahmaans aanduidt. Spreekt men van zijn eigen huis jegens meerderen, dan zegt men umah, terwijl men van de woning eens voornamen sprekende djëro zegt (vgl. Bataksch Wdb. onder bagas I en II); van daar djërondewa "tempel." Zoowel de "hooge" als de "voorname" taal is grootendeels Javaansch, al zijn de woorden heden op Java niet in zwang. Voorbeelden der "hooge" taal zijn: itjal (ilang), makta (bakta) in pl. van ngaba $(a b a)$; rentěn (zelden: nora; ora bestaat hier evenmin als in 't Kawi) in pl. van tusing, using of sing; wentěn in pl. van ada; toja voor jèh; sampun voor suba; sampunang (vetatieve of negatieve imperatief) voor $d a$ (gespeld als hda); glis voor ènggal; duiring of dèrèng voor tondèn; ljarik voor uma "rijstakker"; urung (Jav. wurung) of wangdé (Jav. wandé) voor buung; siki, bij het tellen, voor běsik; malit (Jav.

1 Kahanán is $\mathrm{m}$. i. de oudere en betere vorm; uit $k a+$ hana + an wordt

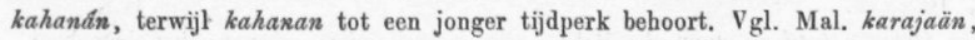
en dgl.

H. K. 
alit) voor tjĕnik; magĕng voor gĕdé; saběh v. udjan (Mal. id., Jav. en Bat. udan); rauh (Jav. rawuh) v. těka; lunga v. luvas; budal of mantuk v. mulih; doh v. djoh (Mal. djauh); djrih v. lakut; margi v. djalan (Mal. id.. Jav. en Bat. dalan); bantèng v. sampi (Jav. sapi); inggih v. nah; punapi v. apa; kaon v. djělé "slecht, leelijk" en kalah "overwonnen worden; "kěkalih "twee" v. dadwa; tětiga v. tatělu (hoogere getallen bezitten geen "hoog" woord.)

Van de "voorname" taal de volgende voorbeelden: tjangkěm in pl. van bungut; tjokor voor batis of bais (van zijne eigene voeten of beenen sprekende zegt men buntul); untu v. gigi; rambut v. bok (vgl. Bat. búk en obuk); pungasan, d. i. pěungasan, van ungas (vgl. Jav. kongas) voor tjunguh "neus;" odak (wdak) v. běborèh; anom v. badjang; rangda (Jav. randa; vgl. boven wangdé voor wandé, en rangdu voor Jav. randu) = balu $;$ istri $=l u h ;$ lanang $=$ mwani, dat vaak mowani uitgesproken wordt) $;$ oka $($ Kawi wěka $)=$ pijanak $;$ mingsiki $=$ misan ; rabi $=$ somah of kurènan (vgl. Kawi kurěn); ida ( $3_{\text {de }}$ pers van een Brahmaan of regeerenden vorst), dane (van een voornaam persoon) $=i j a$ (waarvoor de "hooge" term ipun is, dat in 't Jav. alleen aanhechtsel is); ridjasa $=i s i t ~ " t a n d v l e e s c h$;" mimba $=$ alis; enz.

Dit volsta als eene proeve. Omtrent ridjasa zij opgemerkt dat de Balineezen den klinker in de 3de lettergreep van achteren zeer onduidelijk uitspreken. Weet men dit, dan komt men tot het besluit dat het niets anders is dan een verbastering van 't Kawische rä́djasa (Jav. rëdjasa). Met de bloem van den Râdjasa wordt "fraai tandvleesch" vergeleken: isitengĕmbangridjasa "zijn tandvleesch gelijkt op de Radjasa-bloem," vgl. Bhaumak. bl. 48 r. 1, waar gezegd wordt dat de Râdjasa-bloem zich van haar tandvleesch verwijdert uit vrees de vergelijking daarmeê niet te kunnen doorstaan; voorts Wiwâha, bl. 8 r. 2 v. o. in de Balin. vertaling. Evenzoo is mimba te verklaren uit de poëzie, want het is de Kawi-benaming van den Intaran-boom, waarvan de bladen 't beeld zijn van fraaie wenkbraauwen. Van daar wordt dat blad bij 't kleeden van een lijk door de Balin. als wenkbraauw op 't gelaat gehecht. Hieruit laten zich de twee beteekenissen van 't Jav. imba verklaren, dat wel eene verbastering zal wezen van mimba: men heeft de nasaal, als had die verbale kracht, weg laten vallen; vgl. Kawi en Sund. ngaran, Tag. ngalan met Jav, aran en 't Bal. adan; zie Tob. Spr. Bij 
't toilet van een lijk gebruikt meu ook stukjes staal als tanden, van daar in 't Jav. wadja als $\mathrm{Kr}$. J. van untu.

Het bovenstaande is, dunkt me, voldoende om 't vermoeden te wettigen dat het Jav. Krama vroeger aan de Balin. voorname taal beantwoordde en eerst door den Islam eene andere toepassing heeft gekregen. Zulke Krama-woorden als imba moeten vroeger alleen van personen gebezigd zijn, dewijl het belachelijk is van zijne eigene wenkbraauwen in zoo'n verheven stijl te spreken; of is imba bij Gericke verkeerd als Kr. opgegeven, terwijl het eigenlijk Kr. inggil is? 1

Sommige "voorname" woorden alhier behooren in 't Jav. tot de laagste nitdrukkingen, bijv. tjòkòr, terwijl omgekeerd Kramawoorden van 't Jav. hier soms zeer gemeen klinken, bijv. sĕgaon (sĕgawon), hier alleen met minachting of als scheldwoord gebruikt. Het "hooge" woord kaon (zie boven) is mogelijk te verklaren uit het Jav. awon (Kr. van ala); misschien is het een Krama-vorm van kala, daar de wezens door dit woord angeduid, bij de Balin., even als bij ons de Satan, eene belangrijke rol spelen. Het "voorname" woord voor tjampur "maandstonden", Kawi "onrein", is ngradja en schijnt een werkwoord gevormd uit 't Indische radjaswala,${ }^{2}$ hetwelk in 't Kawi vaak voorkomt; aldus Bhârata-juddha V, 8; XXII, 10. Onder de Indische woorden die in beteekenis en uitspraak nog al verhaspeld zijn, behoort ngrěmbini ${ }^{3}$ stamw. grěmbini, voorname uitdrukking voor mĕngidam "de lusten hebben eener zwangere." Dit kan niet anders wezen dan Skr. garbhinz een fragment van 't Bhaumak. met interlineaire vertaling wordt mětěngakěn "van iets zwanger gaan", zang II, 8, verklaard met nggarbinijang). Met smara, 't fatsoenlijke woord voor pěrljuh, is te vergelijken 't Jav. kama; prana "teeldeel", sarira, voorname term voor 't vrouwelijk pudendum. In plaats van sarira is mij ook opgegeven suruk, hetwelk een zonderlinge verbastering is van Jav. turuk; echter is suruk niet zoo algemeen bekend als sarira. De gemeene man kent al die "voorname" woorden niet. $O$. a. is mij ook opgegeven měkělusa $=$ ngentut (veesten), hetwelk van kalusha moet komen. De

1 Zoo is het inderdaad; zie den 2 den druk van 't Jav. Wdb., bewerkt door Prof. Roorda, i. v. himba.

H.K.

2 Eenvoudiger van Skr. radjah "menses".

H.K.

3 Zóó in den brief; vermoedelijk is het eene schrijffout voor nggrěmbini. H. K. 
opgaven komen niet altoos met elkaar overeen, zoo is mij in plaats van měkělusa ook opgegeven ngampělu, dat in de Balin. eedformule voorkomt.

Ik woon hier vlak bij de desa Baratan, waarvan de bewoners de lijken niet plegen te verbranden. $Z_{i j}$ behooren tot de oorspronkelijke Balineezen, die Bali aga heeten. Dit Bali aga is een scheldwoord, dat men dus in tegenwoordigheid van zulk een Balinees niet mag gebruiken. Het zou me niet verwonderen als dit aga 't Indische woord voor "berg" is, zoodat Bali-aga eigenlijk Berg-balineezen zou beteekenen. In 't Jav. is aga tot arga misvormd; vgl. Jav. barla in plaats van 't Skr. bhalla, te vinden in Bhârataj XXIX, 6. Bekend is het gebruik van gunung in den zin van lompert, even als bij ons "dorper." De naam Bali-angka, door Friederich opgegeven, is mij nog niet voorgekomen. In dit landschap woont een slag van menschen, die, even als de Niassers, de lijken exponeeren. Men zegt dat zij eene andere taal spreken (denkelijk 't oorspronkelijke Balineesch); de plaats heet Sémbiran. Op Sasak ben ik nog niet geweest, omdat ik hier nog te veel te doen heb met afschrijven. Het lijdt geen twijfel of de Sasaksche taal zal veel opheldering geven omtrent het Balin., vóórdat de invloed der Javanen zich deed gelden. Zie hier eenige Sasaksche woorden uit Zollinger's lijst, die tevens Balin. zijn: ading "langzaam", Balin. arlèng, Mak. aring; aměs (ngamĕs "blaauwverven"); badjang; "jong" (vgl. 't Jav. gelijkluidende woord en djabang); basong (in 't Balin. hooge term voor tjitjing, "hond"); bavi (Balin. hoog v. tjèlèng “varken, vgl. Mal. babi); běrak, Balin. běrěk (vgl. Mal. buruk); bujuk Nipah (waarvan de bladeren tot cigaretten dienen); děkung, B. děděkungan "tak om in te enten"; dudukan "belasting" : dujung (? Balin. pujung "ledig); ěnda, negatieve imperatif (B. da); galang "helder, verlicht"; galěng "hoofdkussen"; ganggas "hoog"; gènit "jeukerig"; ngělor "bibberen", als bij koorts; kuris, B. měkuris "zich scheren"; ipo (misschien Duitsche uitspraak voor ibo?; B. ibuk "bekommerd"); isi "vleesch"; kělět "nauw"; kérang, B. kěrĕng "sterk"; kunji, B. kunjiı, curcuma; vgl. Mal.; lala "peper". (B. lalah, scherp op de tong); lèk, de ringvinger; kalěma, des ochtends, B. lěmah, over dag; lïang, verheugd genoegen in iets scheppen; majus, onwillig bij 't werk; mèong kat (Sund. tijger; zie Bataksch Wdb.); muwa (mowa, gelaat); ngènè, aldus (B. kènè, gelijk dit); perajang, hoer (B. ook 
pěndajang, Men, Mal. 't z.); pělją (Duitsche uitspraak zeker; B. heeft bětjat "snel", bijv. loopen); potjal, schadelijden; samělon (B. voorname term $=$ njama, broeder, zuster); njempang, B. hooge term voor singgah, dat hetzelfde beteekent als in 't Mal); tanggu, uiteinde; tatut, B. tjatul, baard-nijptangetje (ook Batav. Mal.); trèng, bamboe, B. tiing (vgl. het geen ik vroeger over den overgang van $r$ in $h$ in 't Bal. gezegd heb).

Vele der door Zollinger opgegeven woorden heb ik overgeslagen omdat de uitspraak mij verdacht voorkomt. Daarenboven heb ik al de woorden overgeslagen die tevens Jav. of Kawi zijn, bijv. bĕgang, rat; de Krĕtabasa heeft wëgang. Een bezoek op Sasak zal meer opleveren. Om de identiteit van trèng met tiing in 't oog te doen vallen, moet ik opmerken, dat wanneer een zustertaal vóór de met $r$ beginnende lettergreep een $\ddot{e}$ heeft, 't Balin. meestal denzelfden klinker vertoont als die in de met $r$ beginnende lettergreep. Bijv. djuuk, ' Jav. djëruk; sè̀, Mal. sĕrej, citroengras; baas, Mal. en Jav. běras; miik, welriekend, Jav. měrik; tunng, Mal. tërung; puun, verbrand; vgl. Mal. pèrun; enz. Het lijdt dus geen twijfel of 't Sasaksche trèng, dat wel těring zal wezen, is Bal. tïing.

De taalvergelijking heeft me niet zooveel voor 't Kawi opgeleverd als ik gedacht had. Dit komt daar van daan, dat men eerst de beteekenis moet kennen eer men eene vergelijking durft maken. Als men bijv. eenmaal de beteekenis van arěk, reiken, weet, is het gemakkelịjk dat woord met B. aděk te vergelijken. Opmerkelijke Kawiwoorden wier zin ik door taalvergelijking kan staven, zijn: sambong, vaartuig, Bug. en Mak.; běngus (bek, snoet; Sund.); pugut, onthoofden, Tag. pogot ; vgl. Jav.; punti, pisang, Lamp. en Sasaksch ; pamasaran, kerkhof, Lamp. en Sund.); hyu, haai, Mal. hiju; poh, mangoboom, B. evenzoo, Mal. páuh, niet pau, zooals Klinkert opgeeft; waruga in Bhaumak. bl. 22, r. 1 v. o, Mak. baruga. Ik zal ze eens verzamelen en $\mathrm{u}$ dan overzenden. Omtrent sommige woorden durf ik niet stellig spreken; zoo bijv. worden de kerels die Kuda Wasèng Sari in den nacht oplichten, in de Wasèng (bl. 1) bërtèh genaamd; is dit 't Lamp. běrtilh, dief?

Bij 't lezen van op Bali afgeschreven HSS. is het niet

1 Gesehreven diuhuk, enz. 
overbodig te letten ook op de fout die de Balinees begaat ten gevolge van zijn orgaan, dat den Kawischen tweeklank $u j$, even als 't Lamponsch alleen slotklank, niet kan uitbrengen. Het Kawische tamuj, ook Lamp., Jav. tamu ' ${ }^{1}$, is in 't Balin. tamyu geworden. In de Krětabasa wordt apuj (ook Lamp.) vaak apwi gespeld ${ }^{2}$; vgl. Bhaumak. bl. 34 , r. 4 en 9 , bl. 231 , r. 15 .

Onder de "voorname" woorden heeft men kasatan voor bëdak, dorst hebben, terwijl 't Jav. asat hier niet in zwang is. Kasatan komt in 't Kawi in dezelfde opvatting voor (zie Bhaumak. bl. 69 , r. 16 ; bl. 231 , r. 10 ), terwijl asat met gulu op bl. 110 , r. 12 aangetroffen wordt. Evenzoo is kataluan, voorname term voor lëngěh, bedwelnd, en tevens voor punjah, dronken, terwijl 't Jav. taluh niet in gebruik is. In 't Balin. is taluh "ei", Mal. lëlur. Het voorname woord voor gělang is pinggěl (Gericke heeft binggĕl, maar Cohen Stuart deelt me mede dat pinggěl ook op Java bekend is; vgl. Kr. Aant. op de Bråtåjoedå, bl. 164). Uit de voorname taal is dus wel wat te halen voor 't Kawi. Naderhand zal ik u een lijst van Kawi-woorden alfabetisch gerangschikt zenden. Vooreerst verzoek ik u deze mededeelingen bekend te maken. Ik hoop dat zij de belangstelling zullen opwekken en zoo eenige zieltjes voor het vak winnen.

De ulu tjandra ${ }^{3}$, waarvan ik in mijn vorig schrijven gesproken heb, kunt ge zien op de gelithogr. Wrĕttasantjaja 8 , rechts, in de woorden ung [1. o̊ , met den Franschen neusklank in mon, enz.] widjajanti.

In den Wiwâha, bl. 92, r. 3, heeft een ander HS. awasâna, volgens de echte Skr. spelling in stede van avaçâna. Het is

I Strikt genomen staat Jav. tamu niet gelijk met tamuy, waarvan de hedendagsche Jav. vorm zou wezen tami; zoo beantwoordt aan Kawi apug Jav. api; aan tumuluy Jav. tumuli. Trouwens, $i$ (eig. $i)=u i$ (Dajaksch oi) is niet alleen Jav., maar ook Maleisch; bijv. bovengenoemd apí "vuur"; Mal. babi, Daj. bavooi; e. a.

H. K.

2 Dit laat zich verklaren uit de omstandigheid dat het Indische schrift geen tweeklank $u i$ (spr. oei) kent. Om nu toch dezen klank uit te drukken, nam men toevlucht tot eene spelling $u y$ (spr. oej), of wi (spr. uit als 't Engelsch vee). Op dergelijke wijze werd vai, vođi "water" geschreven met den in 't Skr. wel bestaanden tweeklank voor $a i$, doch ook, toen die reeds in de uitspraak tot lange $e$ overging, met $a y, d y$.

H. K.

3 Het teeken voor de Anunâsika in 't Skr., ardhacandrika "halfmaantje" genoemd. Klaarblijkelijk is de Balin. naam candra daaruit ontstaan. H.K. 
natuurlijk 't Jav. wasana, verhaspeld tot wussana, door dat men dacht aan wus; in 't Balin. is het in usana overgegaan ; vgl. Bal. urangka $=$ Jav. wěrangka, ulagri $=$ wělagri; zie Homan's Handleiding tot het Batav. Mal. bl. 92, verbetering bij bl. 81,8 . Dit usana is thans nog slechts bekend als titel, nl. Usana Bali "einde van Bali", toen namelijk de Javanen uit Madjapahit overkwamen.

De laagste kaste heet hier anak djaba (lieden buiten kaste); van daar dan ook dat 't gewone Balineesch, bevattende de woorden die van iemand uit de $4_{\text {de }}$ kaste gebezigd kumnen worden, basa djaba heet. Dit djaba is bepaald eene verbastering van 't Kawi java "buiten." Het Krama van Djavoa (Java) en van djaba is, zooals ge weet, djawi, terwijl in modern Kawi ook jawi in plaats van jawa voorkomt. Zou het niet waarschijnlijker wezen den naam Java van dit Kawiwoord af te leiden dan van 't Skr. woord? De Hindus die overkwamen plaatsten al de Javanen buiten de 3 hoogste kasten, evenals die van Madjapahit het met de Balineezen gedaan hebben. In een der laatste zangen, nl. LII, 21 is de uitdrukking ri yawa zeer goed te vertalen met "buiten." Eerst in vers 5 wordt Jawabhûmi vermeld.

Eene zonderlinge liefhebberij in Kawi-Hss. is ook 't gebruik van bh voor $w$, dus bhjoma voor wjoma; bhjomakeça, verkl. in de Krětabasa als Bhalâra Guru, voor wjomakeça; bhâjabja voor wájawja, enz. Ik zou er geen melding van maken zoo zij slechts in de interlineaire vertaling voorkwam, maar ze wordt ook aangetroflen in echt Kawi; of ze daar door eene fout ontstaan is, weet ik nog niet te zeggen. ${ }^{2}$ Overigens weifelen de Kawiwerken nog al dikwijls tusschen $w$ en $b$ [gelijk ook alle Bengaalsche en Hindustansche Hss. en ook alle Calcuttasche uitgaven]; bijv. bahni voor wahni; wadavânala voor badawánala, wiwudhapati voor wibudhapati, kawandha voor kabandha; enz. In de Adiparwa vind ik nu eens Basuki, dan weêr Wasuki, soms kort op elkander. - In de Balin. vertalingen vindt men

1 In 't HS. van Raffles staan slechts 51 Zangen.

H.K.

2 De verwarring tusschen $b$ en $w$ is in de meeste gevallen ouder dan de komst der Hindus op Java. Dat $b$ staat waar $w$ moet staan, en omgekeerd, is wel eene fout tegen de goede uitspraak en spelling van 't Skr., maar tevens eene die door de Javanen slechts overgeërfd is. Bahni in pl. van wahni is niet te wijten aan de Javanen, maar aan de Indische kolonisten, die blijkens deze eigenaardige verwarring af komstig moeten geweest zijn voor ' $t$ grootste deel uit Bengalen, Orissa of oostelijk Hindustân, niet uit Dekkhan, een feit waarop ik reeds vroeger de aandacht gevestigd heb.

H,K. 
vaak woorden met eene $r$ in de derde van achteren gelijk ook in 't Jav. marmata voor manmatha; bijv. mrětanggapati, zon, in pl. van patangga (Bhaumak. blz. 192; vgl. Jav. pratonggapati.) - In pl. van mâlangga, olifant, vind ik in de Tantrî patanggi.

De aanmerking van Cohen Stuart op uwe scheiding Hariwangço Tunggadewa zoude juist zijn, zoo hij opgegeven had Uttunggadewa. Dit Uttunggadewa komt in vele namen van oude Jav. vorsten voor; zoo bijv. heet de vorst waaronder de Adiparwa vervaardigd is, Wikramottunggadewa. Dat Hariwangça der Inscriptie kan men vergelijken met Djajabaja als incarnatie van Wishnu '. - In plaats van sanģ̧aragamacal lees ik sangçaram agacchat. - In Inscr. II, 8, b, vind ik marapxi in pl. van marapuj; dit mar is mij onverklaarbaar, want 't prefix mar is in 't Kawi niet in zwang; vgl. mịne "Opmerkingen," bl. 31. Dat hier de berg Marapi bedoeld is, lijdt geen twijfel. De omzetting van den tweeklank $u j$ in $w i$ is dus vrij oud, hoe verkeerd zij ook moge zijn ${ }^{2}$. Opmerkelijk blijft het dat de naam van den berg zoo overeenkomt met dien van een op de Westkust van Sumatra.

In een der vroegere deelen van 't Tijdschrift van 't Batav. Genootschap, Derde serie, D. II, bl. 221, staat een Balin. eedformulier, dat bijna woordelijk hetzelfde is als dat van de de Inscripties. De lezing er van is zeer aan te bevelen, hoe corrupt het stuk ook zij. Ik heb hier vergeefs naar een goeden tekst gezocht: de dagelijks gebezigde zịnn korter; vgl. t. a. p. bl. 224 .

Anakbi beteekent niet "vrouw en kind," maar alleen "vrouw ;" dit anak is hier vreemd; in 't Balin. beteekent het "individu," pjanak of panak "kind zijnde." Zie hier de plaatsen waaruit de zin met zekerheid kan opgemaakt worden: Bhaumak. bl. 133 r. 3 v. o.; Adiparwa bl. 116 (van mijn HS.): mâti matindih mwang anakbi saha tanaja. In Wirâtap bl. 2 heet de harem van den vorst kânakbyan. In Rânâjana, 3de sarga, zang I, 53 heet het van de onbeschaamde liefdesverklaring van Çûrpanakhâ: tanulahnikananghanakbi; aldaar $6^{\text {de }} \mathrm{S} .$, Zang IV, 11 , van de apen die Swajamprabhâ alleen in een hol aantreffen:

1 Waarom niet eenvoudiger met Sûryawangça? Wanģ̧a is "stamboom, geslacht," maar anģ̧a "deel, incarnatie."

2 Een andere verklaring van dit verschijnsel is beproefd in de lste noot op bl, 29

H. K. 
anèmu tajánakbi rara, rahayu sulakshana manulus, kadi ta wulan djuga gumawang, ja ta kuměmitikanang umah. Uit deze plaats ziet Ge tevens dnidelijk dat $t a$ de vele zinschakeeringen heeft van 't Mal. lah.

Om den brief vol te maken, hier nog een paar woorden.

In Bhaumak. bl. 225, r. 3 , en bl. 22, r. 1 v. o. moet djamanika 't Indische djawanika zijn, verklaard door tawing in Smaradahana, zang II, 1. Hebben we hier met eene bestendigde schrijffout te maken of was die verwisseling algemeen in zwang?' 1 - In 't Kawi vind ik marapwan, rapwan en narapwan in den zin van "opdat" (narapwan in Wirâtaparwa; vgl. Jav. darapon). De Wiwâha, zang 35, str. 6 en 15 heeft rapwan en evenzoo Bhaumak. bl. 135 , r. 3 v o.; de echte vorm is marapian, Krama-vorm van maran, zelden: mara; zie Bhaumak, bl. 109, r. 13. Dit mag wel bekend gemaakt worden, dewijl de Balin. verklaringen dezer woorden vrịj duister zijn. De verbastering tot darapon in 't Jav. is wel een bewijs hoe weinig die taal in haar tegenwoordigen toestand het Kawi kan verklaren.

11.

\section{INHOUDSOPGAVE VAN 'T MAHâBHâRATA IN 'T KAWI.}

(Volgens medededeeling van Dr. H. N. vaN DER TUUK.)

Lwir ning parwwa: Adiparwwa, Sabhâparwwa, Aranyakaparwwa, Wirâtaparwwa, Udyogaparwwa, Bhîshmaparwwa, Dronaparwwa, Karnnaparwwa, Calyaparwwa, Gadâparwwa, Suptikaparwwa, Strîp(r)alâpaparwwa, Açwatthâmaparwwa, Açramawâsaparwwa,

1 Ook in Indische HSS. vindt men den bijvorm (goed of slecht) yamaní; zie Peterburgsche Wdb. onder yavani. Voor Yawana, vindt men dikwijls yamana, en Yaloakoti is om strijd door afschrijvers en uitgevers door Yamakoti vervangen, gelijk ik meer dan eens heb aangetoond. Niet overal waar $m$ en $v$ afwisselen kan men aantoonen dat beide vormen even goed zijn, maar volkomen zeker is het dat cydma en cydroa van ouds her gelijk berechtigd waren; zoo ook Dramida (waarvan Tamil) en Drawid $a$, e. a.

H.K. 